\title{
ANALYSIS OF THE TARGET DECOMPOSITION TECHNIQUE ATTRIBUTES AND POLARIMETRIC RATIOS TO DISCRIMINATE LAND USE AND LAND COVER CLASSES OF THE TAPAJÓS REGION \\ Análise de atributos das técnicas de decomposição de alvos e razões polarimétricas para a discriminação de classes de uso e cobertura da terra na região do Tapajós
}

\author{
Natalia Cristina Wiederkehr ${ }^{1}$ - ORCID: 0000-0003-4002-0981 \\ Fábio Furlan Gama ${ }^{1}$ \\ José Cláudio Mura ${ }^{1}$ \\ João Roberto dos Santos ${ }^{1}$ \\ Polyanna da Conceição Bispo² \\ Edson Eyji Sano ${ }^{3}$ \\ ${ }^{1}$ Instituto Nacional de Pesquisas Espaciais, São José dos Campos, São Paulo, Brasil
}

E-mail: natalia.wiederkehr@inpe.br; fabio.furlan@inpe.br; jose.mura@inpe.br; joao.roberto@inpe.br

${ }^{2}$ Center for Landscape and Climate Research, School of Geography, Geology and Environmental, University of Leicester, Bennett Building University Road - Leicester LE1-7RH. Leicester, United Kingdom

E-mail: pdcb1@leicester.ac.uk

${ }^{3}$ Empresa Brasileira de Pesquisa Agropecuária, Embrapa Cerrados, BR-020, Sobradinhos, Brasília, Brasil

E-mail: edson.sano@gmail.com

Received in February $10^{\text {th }} 2018$

Accepted in October $6^{\text {th }} 2018$

\section{Abstract:}

This study aims to analyze the capability of the target decomposition techniques and the polarimetric ratios applied to the ALOS/PALSAR-2 satellite polarimetric images to discriminate the land use and land cover classes in the Tapajós National Forest region, Pará State. Three full polarimetric ALOS/PALSAR-2, level 1 single look complex scenes were selected to generate the coherence and the covariance matrices to derive the Cloude-Pottier and the Freeman-Durden target decomposition attributes. From the radiometrically calibrated PALSAR-2 images, we generated the backscatter coefficients, the cross polarized ratio (RC; $\mathrm{HV} / \mathrm{HH})$, the parallel polarized ratio (RP; VV/HH) and the Radar Forest Degradation Index (RFDI). The images resulting from these polarimetric attributes were processed by the Maximum Likelihood (MAXVER) classifier coupled with the Iterated Conditional Modes (ICM) contextual algorithm. We found that the classifications derived from the target decomposition attributes, mainly from the CloudePottier technique, with a Kappa index of 0.75 , presented a significant higher performance than those derived from the $\mathrm{RC}$ ratio, RP ratio, and RFDI.

Keywords: Forest mapping; Amazonia; ALOS/PALSAR-2; remote sensing; forest monitoring

How to cite this article: WIEDERKEHR, N. C.; GAMA, F. F.; MURA, J. C.; SANTOS, J. R.; BISPO, P. C. and SANO, E. E. Analysis of the Target Decomposition Technique Attributes and Polarimetric Ratios to Discriminate Land Use and Land Cover Classes of the Tapajós Region. Bulletin of Geodetic Sciences, 25(1): e2019002, 2019. 


\section{Resumo:}

Este trabalho tem como objetivo analisar a capacidade dos atributos das técnicas de decomposição de alvos e dos atributos de retroespalhamento, provenientes das imagens polarimétricas do satélite ALOS/PALSAR-2, para discriminar as classes de uso e cobertura da terra na região da Floresta Nacional do Tapajós (FNT), estado do Pará. Três imagens polarimétricas do satélite ALOS/PALSAR-2 no formato single look complex (SLC), nível 1 de processamento, foram selecionadas para gerar as matrizes de coerência [T3] e covariância [C3] para aplicação das técnicas de Cloude-Pottier e Freeman-Durden referentes à decomposição de alvos. A partir das imagens PALSAR-2 calibradas radiometricamente, foram gerados ainda os coeficientes de retroespalhamento, as razões de polarização cruzada $(\mathrm{RC} ; \mathrm{HV} / \mathrm{HH})$, a razão de polarização paralela (RP) e o Radar Forest Degradation (RFDI). As imagens derivadas de todos esses atributos polarimétricos supracitados foram processadas pelo classificador de Máxima Verossimilhança (MAXVER) integrado ao algoritmo contextual Iterated Conditional Modes (ICM). As classificações derivadas dos atributos relativos às técnicas de decomposições de alvos, principalmente a de Cloude-Pottier, com índice Kappa de 0,75, apresentaram desempenho significativamente superior àqueles derivados das razões RC, RP e RFDI.

Palavras-chave: Mapeamento florestal; Amazônia; ALOS/PALSAR-2; sensoriamento remote; monitoramento florestal

\section{Introduction}

Information derived from radar systems are important for mapping and monitoring tropical landscapes due to the persistent cloud coverage that often occurs in most of the tropics. Synthetic Aperture Radar (SAR) datasets are sensitive to variations in forest structure (Kasischke et al. 1997; Santos et al. 2003; Treuhaft et al. 2004), allowing to understand the interaction between emitted energy and the constituents and structure of the canopies at different ecological stages. This capability enables to update the landscape characterization and to discriminate different land use and land cover (LULC) types (Li et al. 2012).

Radar polarimetry registers the amplitude and phase information that enables a higher knowledge about target's physical and dielectric properties, allowing the discrimination of these targets and their representation on maps. By using the decomposition techniques of the polarimetric data, we can identify and analyze different types of scattering mechanisms that occur during the interaction process between the target and the emitted signal in the microwave spectra (Boerner et al. 1998). On the other hand, the attributes extracted from the radar backscattered signals indicate level of intensity of this backscattering process. Numerical models such as the polarization ratios have been developed to highlight the differences between the microwave spectral bands and/or polarizations that are more sensitive in certain configurations and field conditions.

Currently, there are several satellite radar systems available for the community users, including, among others, the TerraSAR/TanDEM-X mission (X-band, $\sim 1 \mathrm{~cm}$ of wavelength), CosmoSkyMed (X-band), RADARSAT-2 and Sentinel-1A/B (C-band, $\sim 5 \mathrm{~cm}$ ), and the Phase Array L-band Synthetic Aperture Radar (PALSAR - L band, $\sim 23 \mathrm{~cm}$ ) on board of Advanced Land Observing Satellite (ALOS). A number of research is using SAR products for mapping and monitoring the Brazilian Amazon. Bispo et al. (2012) compared ALOS/PALSAR-1 polarimetric data and geomorphometric, floristic and structural data to discriminate primary and secondary forest 
typologies. Silva (2014) utilized ALOS/PALSAR-1 and TerraSAR/TanDEM-X data for aboveground biomass modeling. Martins et al. (2016) evaluated the ALOS/PALSAR-1 sensitivity to detect forest degradation caused by successive forest fires.

There have been efforts to improve techniques of information extraction based on the target decomposition theorems, including those derived from the backscatter coefficients applied to studies involving landscape characterization and variations in the anthropogenic processes. This study aimed to analyze the potential of attributes derived from backscatter coefficients and from target decomposition techniques of ALOS/PALSAR-2 polarimetric data for the LULC discrimination in the Tapajós National Forest (TNF) region and surrounding areas.

\section{Data and Methods}

\subsection{Study area}

The study area covers part of the Tapajós National Forest region and surroundings, along the BR-163 (Cuiabá-Santarém) highway and between $2^{\circ} 56^{\prime} 26.47^{\prime \prime}$ and $3^{\circ} 12^{\prime} 23.69^{\prime \prime}$ of south latitude and between $55^{\circ} 3^{\prime} 27.93^{\prime \prime}$ and $54^{\circ} 54^{\prime} 25.52^{\prime \prime}$ of west longitude (Figure 1 ). The part of the study area encompassed by the TNF is dominated by the open and dense Ombrophilous forests in different ecological successional stages. Inside the forest, there are some sites with selective logging activities (sustainable timber exploitation). Outside the TNF, we find fishbone-like structured, extensive areas of mechanized agriculture, grazing, and historical settlements of colonization, with family-based-agriculture. Some fragments of the natural forest outside the TNF are degraded by the uncontrolled timber exploitation or by fires.

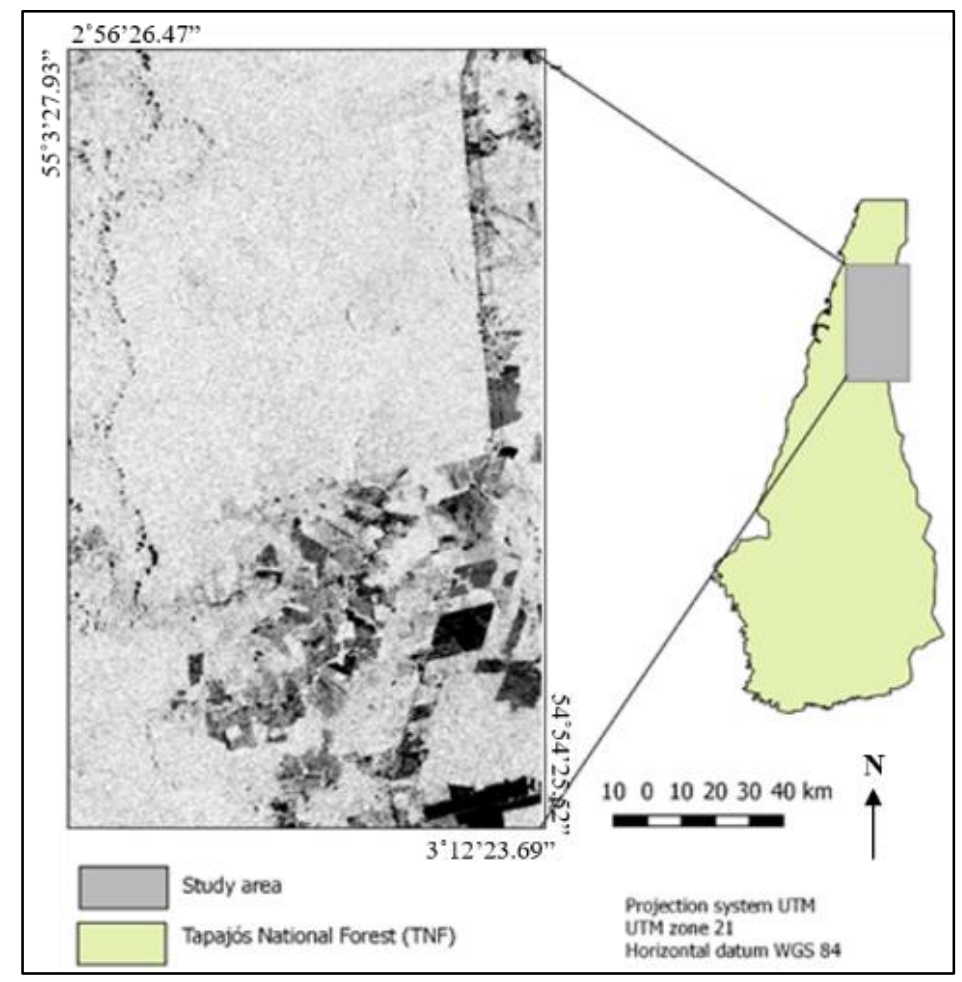

Figure 1: Location of the study area. 


\subsection{Radar images processing and classification procedures}

The methodological procedures adopted in this study are shown in Figure 2. Three ALOS/PALSAR-2 images in the quad-pol polarization - HH, VV, HV and VH - acquisition mode in the StripMap format, with pixel spacing of $3.13 \mathrm{~m}$ in the range direction and $2.86 \mathrm{~m}$ in the azimuth direction were obtained from the ALOS User Interface Gateway (AUIG2) platform, under the ALOS Kyoto \& Carbon Initiative, an international collaborative project led by Japan Aerospace Exploration Agency (JAXA). The overpasses were on April 17, 2016 and May 1, 2016. The images were processed in the Sentinel Application Platform 5.0 (SNAP) software. The coherence [T3] and covariance [C3] matrices were generated and resampled by a spatial average (multilook) 3 pixels $\times 3$ pixels to decrease the speckle noise, yet preserving the images details. Thus, the pixel spacing was converted to $8.5 \mathrm{~m} \times 9.5 \mathrm{~m}$ in range and azimuth directions, respectively.

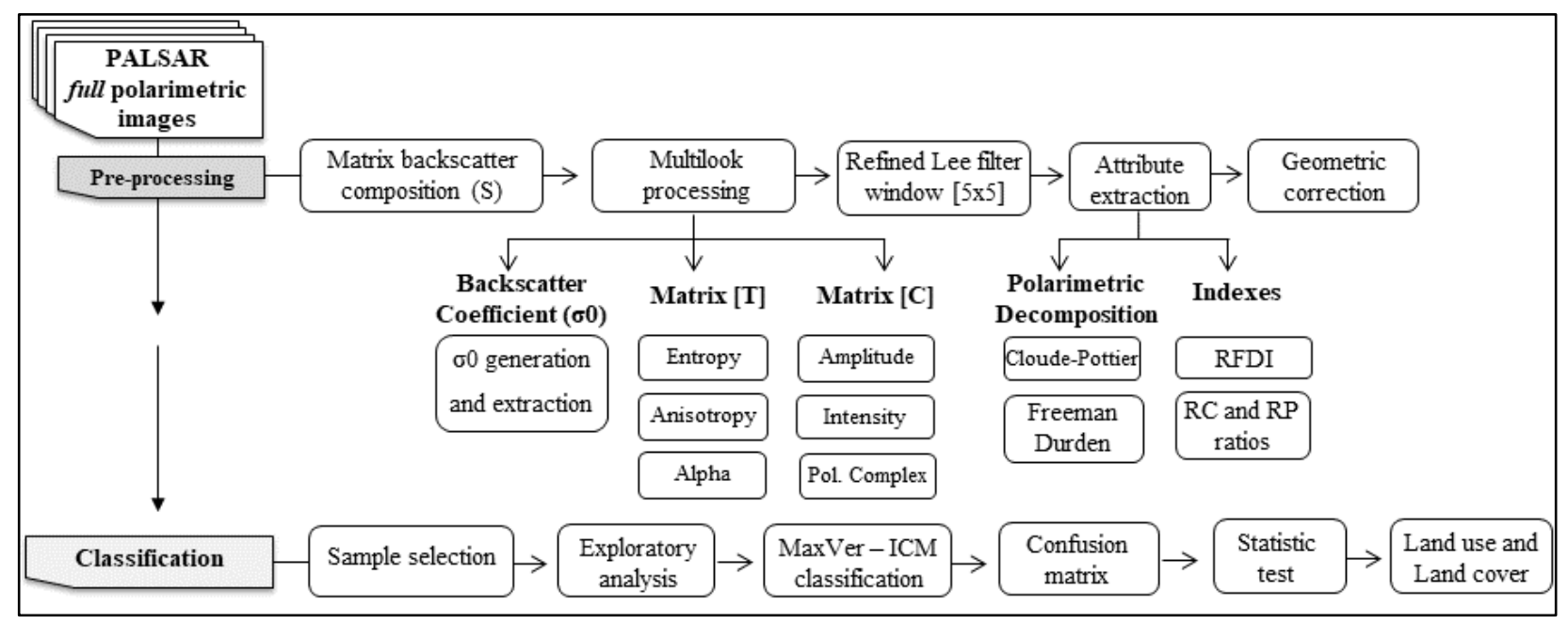

Figure 2: Flow chart of ALOS/PALSAR-2 image processing activities.

The matrices were filtered with the Refined Lee filter (Lee et al. 1999) with the 5 pixels $\times 5$ pixels window size. Next, the images were processed by the Cloude-Pottier polarimetric decompositions techniques to extract the entropy $(H)$, anisotropy $(A)$ and alpha angle $(\alpha)$ attributes (Cloude and Pottier 1996), as well as by the Freeman-Durden decomposition target model to obtain the surface scattering $\left(P_{s}\right)$, double bounce $\left(P_{d}\right)$ and volumetric $\left(P_{v}\right)$ attributes (Freeman and Durden 1998). The radiometric calibration of SAR data was carried out to obtain the backscatter coefficients that allowed generating the cross and the parallel polarization ratios (RC - HV/HH and PR - HH/VV, respectively) (Henderson and Lewis, 1998), as well as the Radar Forest Degradation Index (Saatchi et al. 2010). The last procedure consisted of the geometric correction of the attributes through geocoding.

After the image processing, we conducted an exploratory analysis to select the best attributes derived from the decompositions and/or ratio-based indexes in order to evaluate the discriminatory capability of the polarimetric attributes for discrimination of the investigated thematic classes. Boxplots related to each attribute were related to the training set and prepared for such analysis. Samples with low or none capacity to discriminate the investigated classes were then removed from analysis. The following LULC was considered based on the field survey conducted close to the ALOS overpasses. The land cover and land use classes considered in this 
study are: Primary Forest (PF); Advanced Secondary Succession (SS3); Intermediate Secondary Succession (SS2); Initial Secondary Succession (SS1); Degraded Forest (DG), Bare Soil and Fallow (BS); Well-Managed Pasture (WP); Poorly-Managed Pasture (PP); Cropland (CR); and Water Bodies (WB).

Tadesse et al. (2017) mentioned that the classification accuracy can be obtained by using the ground truth data collected from field using GPS, satellite images and other source. In this present study, the data selection method for calibration was through stratified random sampling. To evaluate the performance of the classifications, we applied the hold-out method cross validation. The data set was separated into two sets: for the training and validation steps of the classifications, we used a set of 200 field samples, divided into 126 training samples and 74 reference samples After the data collection, a contingency table was used to analyze the Kappa agreement coefficient, overall accuracy, producer's accuracy and consumer's accuracy.

The images derived from the target decomposition techniques and from the ratios that express the physical characteristics of the backscattering process were classified by the MAXVER pixel-based classifier, integrated with the Interated Conditional Modes (ICM) contextual algorithm. The ICM algorithm consists of a classification technique that incorporates spatial dependence to refine the initial classification (Freitas et al. 2007; Nery et al. 2013; Pereira et al. 2016). The results of all classifications were used to generate the confusion matrices in order to determine the accuracy of the classification that was based on Kappa index and Z-test.

\section{Results}

\subsection{Sensitivity of polarimetric attributes for LULC mapping}

The exploratory sensitivity analysis of the polarimetric attributes showed that the CloudePottier target decomposition components presented a good capacity to discriminate between forest covered areas (with different ecological stages) and other classes with less biomass content (Figure 3). However, its potential to discriminate secondary successions with different stages was lower, mainly in the $H$ and $\alpha$ components. 

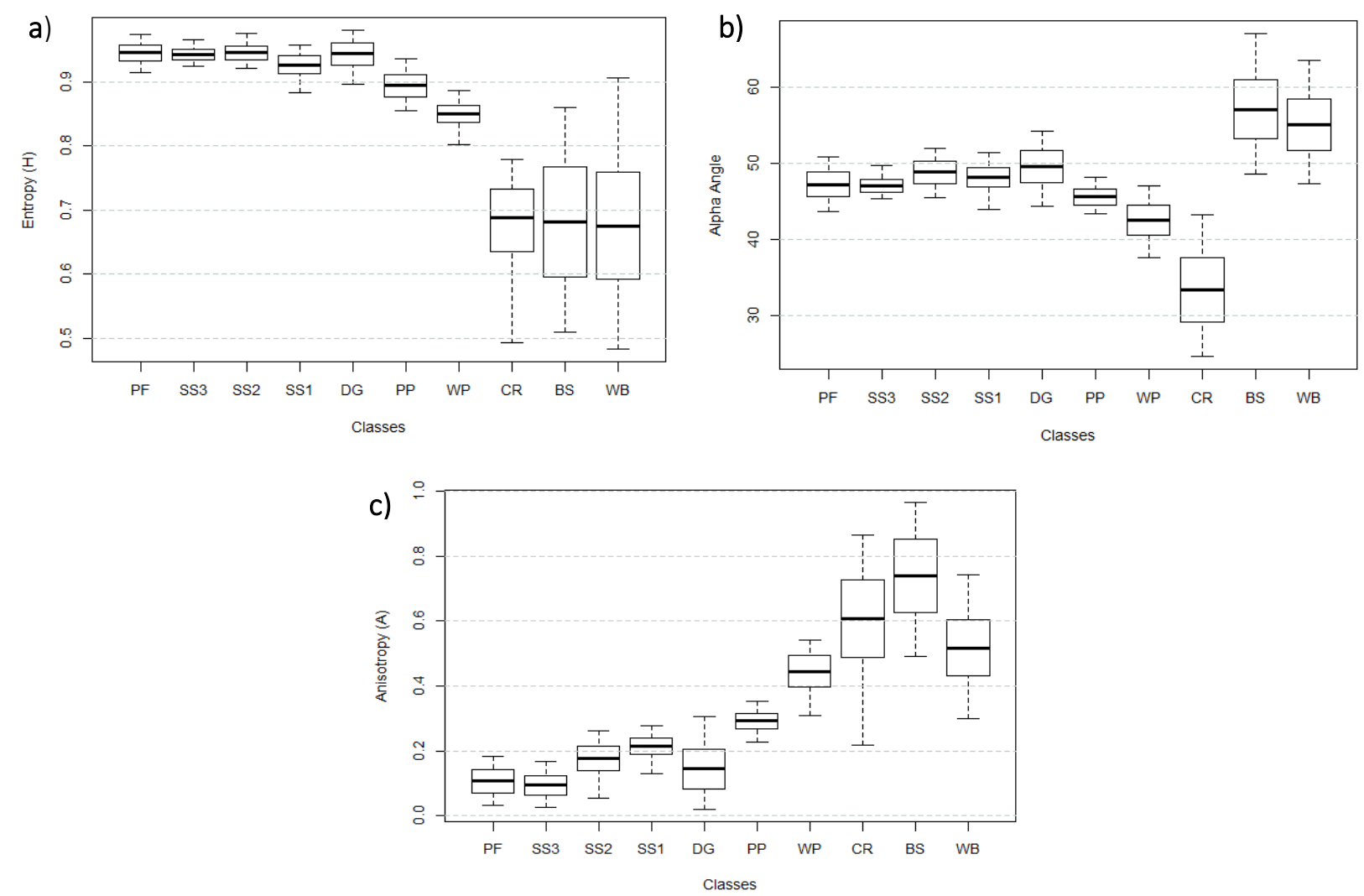

Figure 3: Boxplots representing the distribution of the thematic classes over the entropy $H(a)$, alpha angle $\alpha$ (b) and anisotropy $A$ (c) attributes derived from the Cloude-Pottier decomposition. PF: Primary Forest; SS3: Advanced Secondary Succession; SS2: Intermediate Secondary Succession; SS1: Initial Secondary Succession; DG: Degraded Forest; PP: Poorly-Managed Pasture; WP: Well-Managed Pasture; CR: Cropland; BS: Bare Soil and Fallow; and WB: Water Bodies.

The relatively high average values of $H$ for PF $(H=0.945)$, SS2 $(H=0.945)$, and SS1 $(H=$ $0.926)$, indicate radiometric similarity between these classes. The $\alpha$ attribute also showed overlapping. The average values of $\alpha$ for the PF, SS2, and SS1 were $47.2^{\circ}, 48.7^{\circ}$, and $48.1^{\circ}$, respectively. The $A$ attribute showed higher sensitivity to the different stages of succession, presenting average values of $0.10,0.17$, and 0.14 for PF, SS2, and DG, respectively. This indicates higher variability of radiometric responses among classes when compared with $H$ and $\alpha$ attributes. The $A$ attribute was even more sensitive than the others to discriminate $D G, P P, W P, C R, B S$ and WB.

The $P_{v}$ attribute, obtained by the Freeman-Durden decomposition, showed higher variability of radiometric responses for SS1, PP, WP, CR, BS, and WB (Figure 4). The PF and SS3 presented similar radiometric responses. However, PF and SS3 showed higher values, enabling to distinguish them from the SS2 and SS1. In the $P_{d}$, attributes, the BS and WB presented highest values, with an average values of 107.96 and 107.25, respectively. The SS1 presented the highest value (average of 102.29). The PP and WP classes were poorly discriminated in this attribute, presenting an average of value of 100.08 for PP and an average value of 97.63 for WP.

The $P_{s}$ attribute reached higher discrimination among SS2, SS1, and DG classes, especially for SS1, which presented the highest value among the secondary vegetation categories. The 
highest scores were obtained for the classes presenting low or no vegetation. The $P_{s}$ attribute showed low capacity of separation between CR and BS.
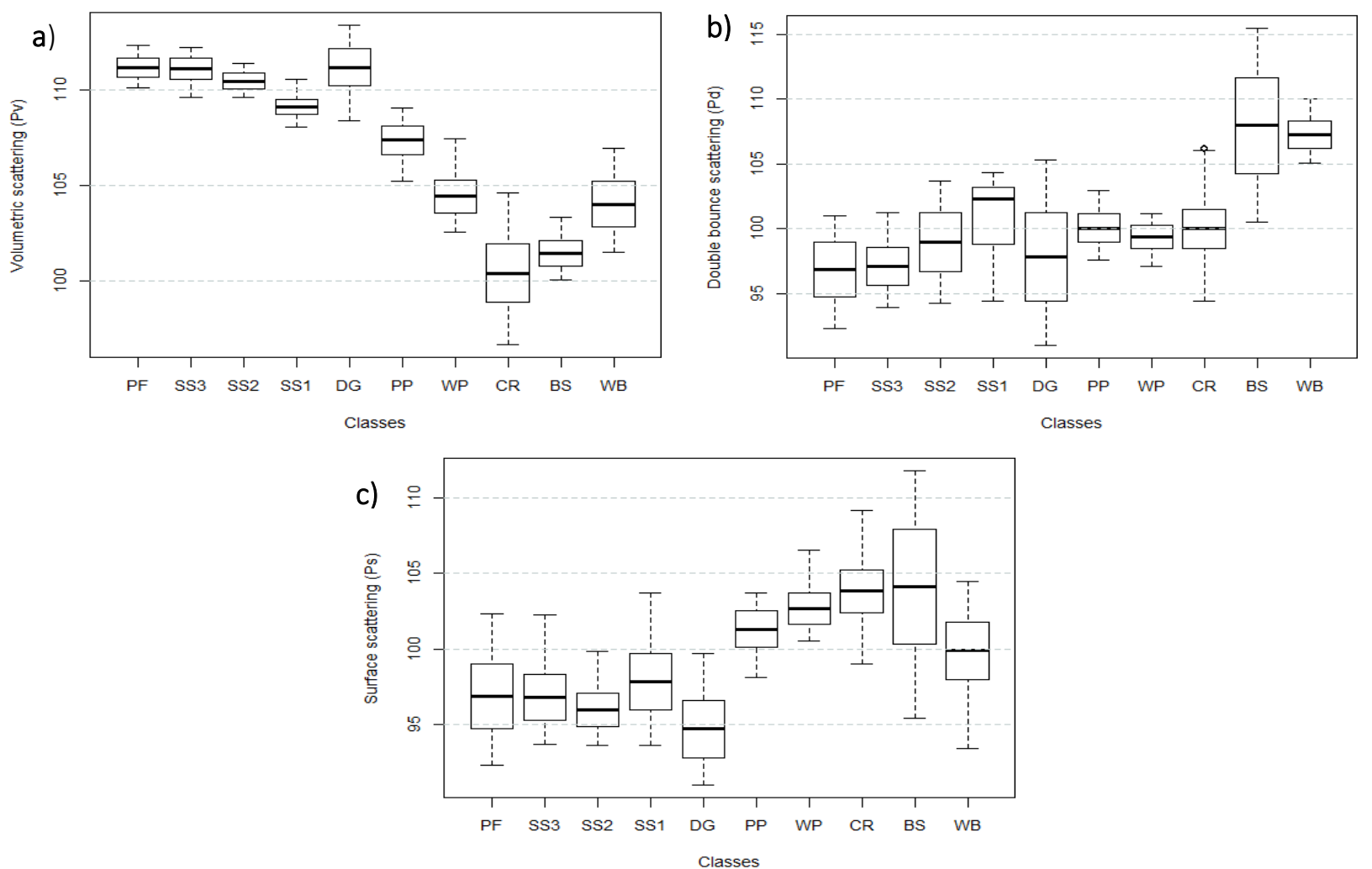

Figure 4: Boxplots representing the thematic classes distribution over the $P_{v}(\mathrm{a}), P_{d}(\mathrm{~b})$, and $P_{s}(\mathrm{c})$ attributes of Freeman-Durden decomposition. See Fig. 3 for class identification.

The RP attribute presented the highest backscatter values, mainly for PF and SS3, which are the classes with highest forest structures (Figure 5). Lower values were obtained by the SS2 and SS1, the secondary vegetation with less biomass and more simple vegetation structure in comparison to the SS3 and PF. The PP and WP presented high radiometric similarity, that is, they were not possible to be differentiated from this attribute. However, the CR, BS, and WB were able to be discriminated each other by this attribute.

The $R C$ attribute presented high radiometric similarity for $C R, B S$, and $W B$, with average values of $0.13,0.12$, and 0.14 , respectively (Figure 5 ). The secondary vegetation classes presented average values of 0.44 for SS3, 0.30 for SS2, and 0.25 for SS1, indicating a high capability to discriminate each other.

The RFDI exhibited lower values for SS3, SS2, and DG, with average values of $0.46,0.56$, and 0.49 , respectively (Figure 5). Values higher than 0.60 were obtained by the SS1, DP, WP, CR, $\mathrm{BS}$, and WB classes. The boxplot analysis indicated that the RFDI attribute showed low capacity to discriminate $C R, B S$, and WB classes, as well as between PP and WP. 

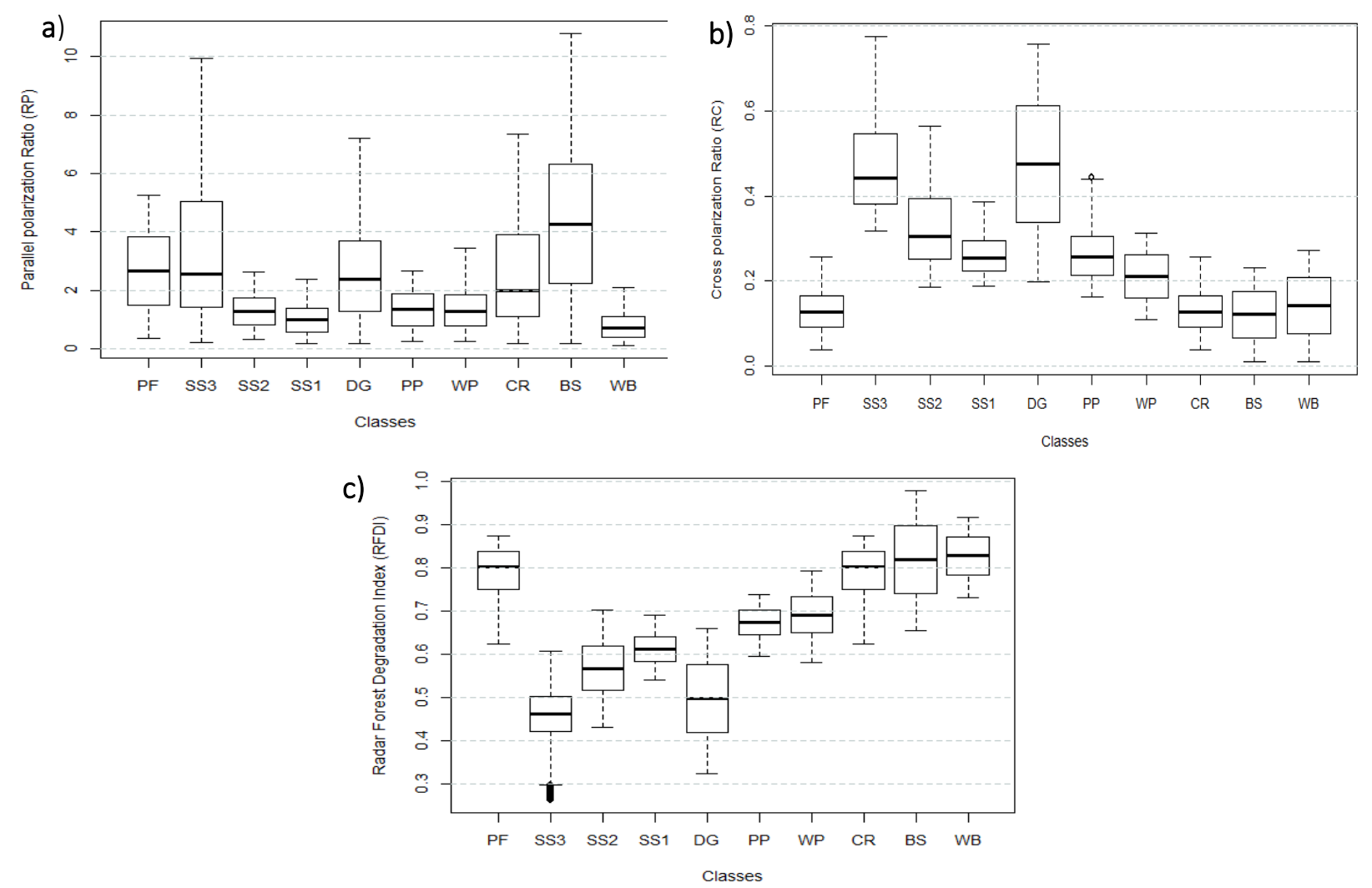

Figure 5: Boxplot representing the thematic classes distribution over the parallel-polarized ratio $(\mathrm{RP})(\mathrm{a})$, cross-polarized ratio (RC) (b), and the Radar Forest Degradation Index (RFDI) (c) attributes.

\subsection{Classification results by MAXVER-ICM algorithm}

The best MAXVER-ICM classification result was obtained by the Cloude-Pottier decomposition attributes, with an overall accuracy of 0.80 and a Kappa index of 0.75 , rated by Landis and Koch (1977) as substantial agreement. The second best result was obtained by the Freeman-Durden decomposition attributes, with a Kappa index of 0.56 . The RFDI, RC, and RP attributes showed Kappa indexes of $0.23,0.20$, and 0.13 , respectively. The statistical difference between the Cloude-Pottier decomposition attributes and the RC was 17.64 while the difference between the Cloude-Pottier and RP was 21.42. Finally, the difference between the Cloude-Pottier and RFDI was 16.53 (Table 1).

Table 1: Z-test applied to Kappa indexes.

\begin{tabular}{cccccc}
\hline & Cloude Pottier & Freeman Durden & RC & RP & RFDI \\
\hline Cloude Pottier & 0.0 & & & & \\
Freeman Durden & 5.9 & 0.0 & & & \\
RC & 17.6 & 10.8 & 0.0 & & \\
RP & 21.4 & 14.1 & 3.2 & 0.0 & \\
RFDI & 16.5 & 9.8 & $-0.9 *$ & -4.1 & 0.0 \\
\hline \multicolumn{7}{c}{ * Difference not significant at the 95\% of confidence level. }
\end{tabular}


By analyzing the two-dimensional spatial configuration of the Cloude-Pottier decomposition attributes (Figure 6), it is noticeable that the combination between $\alpha$ and $A$ attributes, as well as between $\alpha$ and $H$ attributes, improved the discrimination of the CR class. The confusion matrix indicated that $89 \%$ of the samples were classified correctly (Table 2). These two combinations also presented high capacity to discriminate WP, without confusion with any other class.

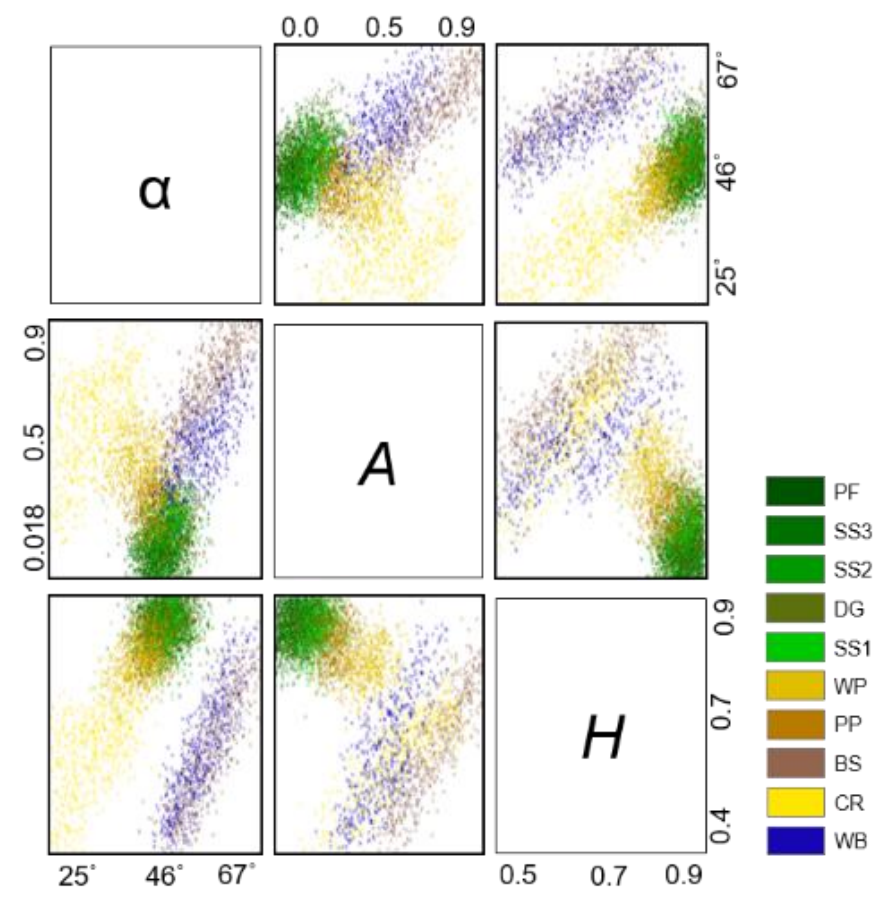

Figure 6: Space attribute configuration of the LULC classes, according to the Cloude-Pottier decomposition technique.

Table 2: Confusion matrix of the image classification derived from the Cloude-Pottier decomposition technique. See Fig. 3 for class identification.

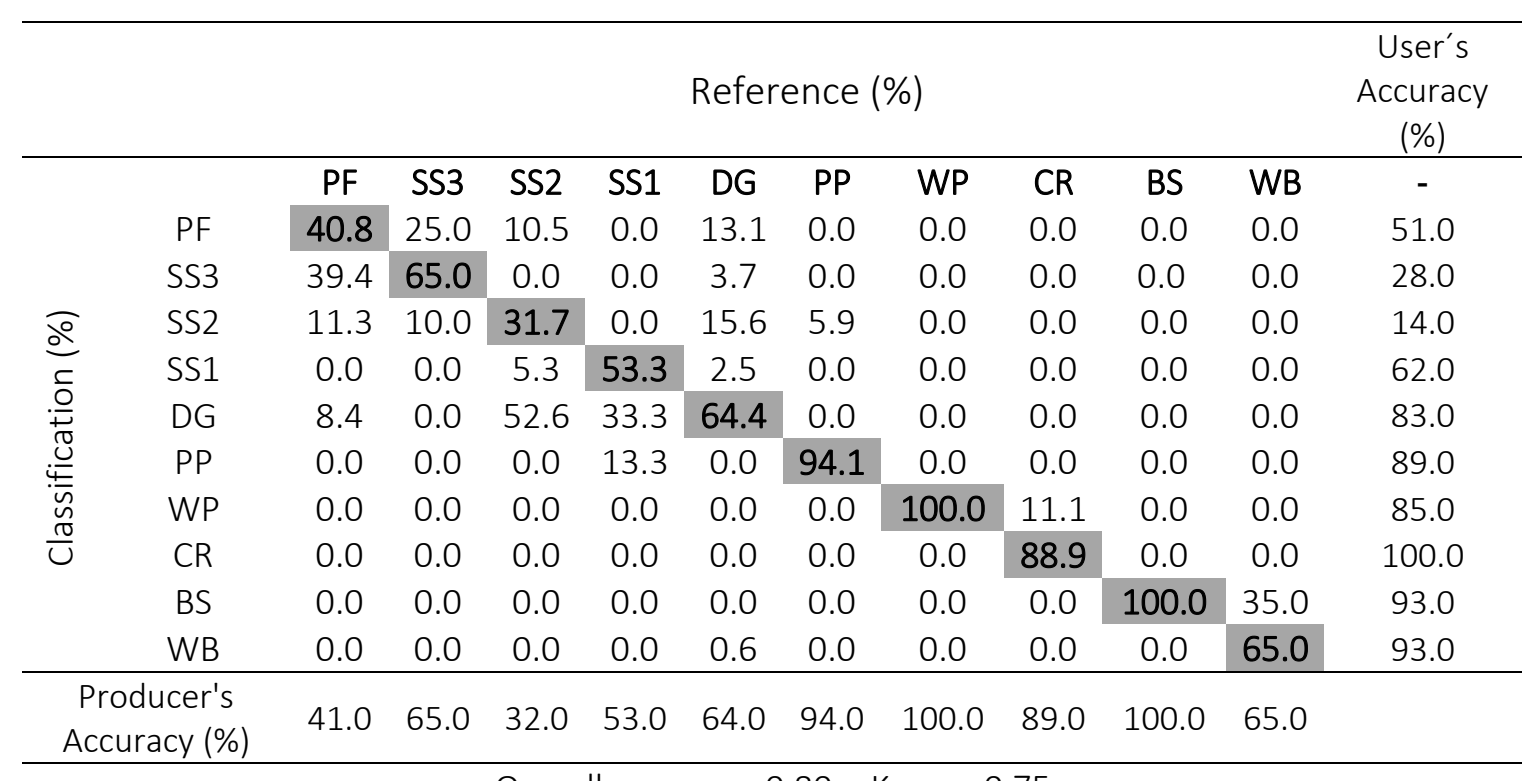

Overall accuracy: 0.80 - Kappa: 0.75 
The combination of $\alpha$ and $A$ attributes demonstrated high capacity to discriminate the PP and BS. According to the confusion matrix (Table 2), the PP presented a classification accuracy of $94.1 \%$, with $5.9 \%$ of misclassification with SS2. The BS presented $100 \%$ of accuracy. According to the two-dimensional space attributes, all combinations resulted in low capacity to differentiate PF, SS3, SS2, SS1, and DG. The accuracy of PF, SS3, SS2, SS1, and DG classes were $40.8 \%, 65.0 \%$, $31.7 \%, 53.3 \%$, and $64.4 \%$, respectively. The lower classification performance was found for the SS2 class and the highest for the WP and CR.

Figure 7 shows the potential of the Cloude-Pottier group of decomposition attributes to produce LULC maps. These attributes produced the most reliable LULC map of the TNF region using ALOS/PALSAR-2 data.

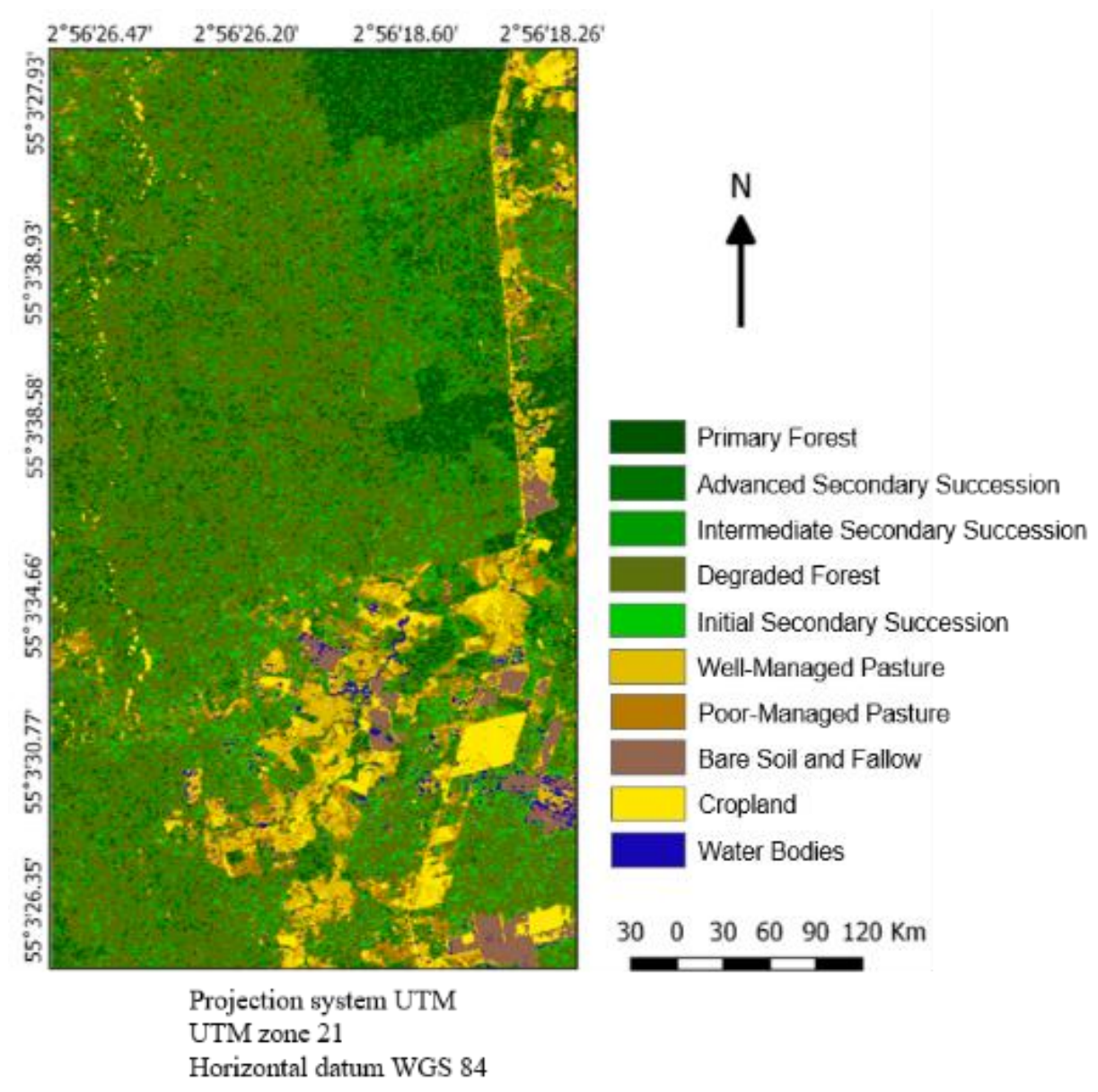

Figure 7: Spatial distribution of LULC classes derived from the Cloude-Pottier decomposition technique using ALOS/PALSAR-2 image. See Fig. 3 for class identification. 


\section{Discussions}

The attributes derived from Cloude-Pottier decomposition technique showed good potential to discriminate between the natural forest classes and less or no vegetation covered classes. However, the potential to distinguish ecological succession classes, utilizing $H$ and $\alpha$ attributes was not so good. The $H$ attribute showed high mean values for the forest classes in different successional stages, indicating that the different scattering mechanisms contributed similarly the backscattering process. The mean $\alpha$ value for BS indicates how the effect of different soil preparation can directly influence the backscattering process. According to Brisco et al. (1991), plowed areas can produce rougher surfaces when compared with areas with or no mechanization, producing strong backscatter and increasing the contribution of $\alpha$ attribute.

On the other hand, the $A$ attribute showed higher sensitivity to discriminate the thematic classes considered in this study, presenting higher variability in the radiometric responses compared with $H$ and $\alpha$ attributes. $A$ attribute still presented high potential among the CloudePottier decomposition attributes to discriminate the DG class, mainly the forestlands affected by fire (between October/2015 and February/2016) that occurred over the study area.

Among the Freeman-Durden attributes, $P_{v}$ showed low separability between the PF and SS3, indicating overlap. In spite of the overlap, PF and SS3 presented higher average values of discrimination regarding SS2 and SS1. This result was expected, mainly for PF and SS3 classes, in function of higher forest cover densities, which is composed by high number of extracts, enabling the occurrence occasion of volumetric scattering. Narvaes et al. (2010), in their study involving aboveground forest biomass modeling using PALSAR-1 full-polarimetric data in the TNF region, also indicated a significant contribution of $P_{v}$ attribute values to the primary and secondary forest classes. Kuplich et al. (2009), concerning the Freeman-Durden decomposition attributes, also showed that the $P_{v}$ component has higher capability to discriminate LULC classes in the TNF region.

The $P_{d}$ attribute showed high average value for WB, indicating possible interaction of water body surface with its surroundings. Among the classes with natural vegetation, SS1 presented high average values, showing a regular growth of pioneer species in different strata. This stratum is probably composed by initial succession stage distributed irregularly on the environment. The results obtained by the $P_{d}$ attribute for the SS1 classe is in agreement with the result presented by Narvaes et al. (2010).

Regarding the RC derived data analysis, the discrimination between PP and WP and between PF and SS3 was poor. Concerning the RP derived data, the higher backscatter values were well related to the different successional stage classes, mainly PF, SS3, and SS2. The values of classes are directly to the types of the canopies structured in different regeneration stages. The canopy of early and/or intermediate stage of succession normally are lower in size and density in relation to those in more advanced stage of regeneration. The RP data presented overall higher capacity to discriminate WB from the other classes with lower vegetation cover.

The RFDI results presented similar results from those presented by Saatchi (2010). Low values of the different succession classes analyzed (i.e., around 0.0) are related to the high structure and vegetation density. The lower average values presented by these ecological succession classes in HV polarization is mainly due to the volumetric scattering mechanisms. The higher values related to the RFDI (i.e., around 1.0) are related to the classes with less forest cover. This index presented low discrimination capacity between PP and WP and between WB, BS, and CR. 
In the comparative analysis involving two-dimensional space attribute, all paired combinations presented low discrimination from the SS3, SS2, and SS1 classes. The ecological succession showed high backscatter values in the $H$ and $P_{v}$ attributes. Dense forests and/or natural forests, present higher backscatter values in comparison with the areas with less vegetation cover (CCRS, 1997).

The group of attributes from Cloude-Pottier decomposition showed higher potential to discriminate the LULC classes considered in this study (Table 3). It was found that the groups of attributes derived from the Cloude-Pottier and Freeman-Durden decompositions presented higher classification performance. For the forest ecological succession classes, all groups of attributes showed low classification performance. The Cloude-Pottier decomposition exhibited the highest percentage of classification scores, except the PF which presented better discrimination capability for the RFDI component. Among the classes with low or no vegetation cover, the Cloude-Pottier and Freeman-Durden decompositions presented the best performances to discriminate these classes. The attributes derived from the backscatter coefficients presented low discrimination capacity.

Table 3: Classification performance of the Cloude-Pottier, Freeman-Durden, RC, RP, and RFDI decomposition techniques. For class identification, see Fig. 3.

\begin{tabular}{ccccccccccc}
\hline & PF & SS3 & SS2 & SS1 & DG & PP & WP & CR & BS & WB \\
\hline Cloude-Pottier & 40.8 & 65.0 & 31.6 & 53.3 & 64.4 & 94.1 & 100.0 & 88.9 & 100.0 & 65.0 \\
Freeman-Durden & 36.6 & 25.0 & 26.3 & 46.7 & 38.7 & 70.6 & 100.0 & 100.0 & 88.9 & 90.0 \\
RC & 29.6 & 45.0 & 26.3 & 40.0 & 14.4 & 52.9 & 52.9 & 0.0 & 27.3 & 50.0 \\
RP & 36.4 & 0.0 & 15.8 & 20.0 & 0.0 & 52.9 & 26.5 & 0.0 & 5.9 & 90.0 \\
RFDI & 62.0 & 40.0 & 5.3 & 40.0 & 16.2 & 52.9 & 44.1 & 11.1 & 27.3 & 25.0 \\
\hline
\end{tabular}

For the RP data, among the analyzed classes with less and/or no vegetation cover, the best classification results was obtained for the WB class, with $90 \%$ of the agreement. For the classes with natural vegetation cover, the best classification result was obtained for the PF class, with $36.4 \%$ of accuracy. For the RC data, the highest accuracies were related to the PP and WP classes, both with $52.9 \%$ of accuracy. Regarding the natural vegetal cover classes, SS3 obtained the highest percentage, with $45 \%$ of its samples classified correctly. Concerning the other investigated classes, this data exhibited low discrimination capacity.

The RFDI presented the best classification result among the investigated group of attributes to discriminate PF class, with $62.0 \%$ score. This result points out a higher backscatter contribution in $\mathrm{HH}$ polarization, which shows more sensitivity for volumetric scattering. For the other classes, this index showed poor discrimination performance.

The Cloud-Pottier decomposition presented the best results to discriminate SS3, SS2, SS1, DG, PP, and BS classes. The WP showed $100 \%$ accuracy for the classifications involving CloudePottier and Freeman-Durden decompositions. On the other hand, CR class presented 100\% accuracy in the classification involving the Freeman-Durden attributes. The WB was better discriminated by the RP data and Freeman-Durden groups of attributes, with $90 \%$ accuracy. Among all the attributes analyzed to discriminate PF, RFDI presented the best classification accuracy, demonstrating the potential of this attribute in tropical areas, where, landscape is dominated by forest, either primary or degraded by the timber exploration. 


\section{Conclusions}

In this study, we found that the Cloude-Pottier and the Freeman-Durden decomposition attributes presented higher Kappa indexes when compared with the Kappa index obtained by the $\mathrm{RC}$ and RP data expressed in terms of the backscattering values. The classification results obtained from the polarimetric ratios and from the RFDI index demonstrated low efficiency of these attributes.

The Cloude-Pottier decomposition, with a Kappa index of 0.75, was the most effective technique. The classification results demonstrated the capacity of the ALOS/PALSAR-2 full polarimetric data, processed by the target decomposition techniques, to discriminate LULC classes over the tropics.

Regarding the natural vegetal classes, the biggest differences among the ecological successions were obtained by the $A$ and $P_{v}$. attributes. The $A$ attribute exhibited the highest potential to discriminate the DG class, especially when the degradation is related to the disturbance by fire.

The pressures over natural resources caused by forest conversion in several land use types and the high level of landscape fragmentation have been affecting the local biodiversity that is still being preserved inside of the TNF. This makes the long term studies of the LULC dynamics around Tapajós area highly relevant. In this case, radar images are very important because of the already well-known capability of obtaining data regardless of cloud condition and solar illumination conditions, among others. The radar data, processed by the decomposition techniques, can improve the discrimination capability of LULC classes, as demonstrated by this study.

This study showed the potential of the L-band polarimetric SAR attributes in context of monitoring tropical areas, especially considering initiatives such as the REDD+, the Global Forest Observations Initiative (GFOI), and the FOREST 2020 whose main goal is to support the national forest monitoring systems in different countries.

The results obtained and presented in this research do not exhaust the thematic classes discrimination by the MAXVER-ICM classifier from radar data processed by the target decomposition techniques. Recent investigations have aimed the integration between radar and optical data (Pereira et al. 2013, 2016; Otukei et al. 2015), in which data processing is directed towards the wavelet transforms or hybrid classifier approaches, such as cited by Lu et al. (2013). However, such actions need to take into consideration the inter and intra-pixel complexity in tropical landscapes, the loss of variables in the classifier models by attribute selection or by radiometric transformations intrinsic to the fusion of multi-source or multi-data. Therefore, scientific effort has been directed to the use of classifiers such as Random Forest that has been applied for both optical-based reflectance measures and SAR polarimetric-based texture metrics (Hagensieker et al. 2018; Pavanelli et al. 2018) to increase the accuracy level on LULC class stratification. 


\section{Acknowledgements}

The authors are grateful to the following institutions: Coordination for the Improvement of Higher Education Personnel (CAPES); Brazilian National Council for Scientific and Technological Development (CNPq); National Institute for Space Research (INPE); Chico Mendes Institute of Biodiversity Conservation (ICMBio) (Process 38157-5); and the Large Scale Biosphere-Atmosphere Experiment in Amazonia Program (LBA/Santarém). P. C. Bispo was supported by the European Union's Horizon 2020 Research and Innovation Programme under the Marie Skøodowska-Curie grant agreement No. 660020. The ALOS-2 scenes were provided by the Japan Aerospace Exploration Agency (JAXA), under the Kyoto \& Carbon Initiative.

\section{REFERENCES}

Bispo, P. C.; Santos, J. R.; Valeriano, M. M.; Graça, P. M. L. A. 2012. Efeito da topografia na resposta polarimétrica de floresta tropical em imagens PALSAR/ALOS. Ambiência, 8, 501-510.

Boerner, W. M. et al. 1998. Polarimetry in radar remote sensing: basic and applied concepts. In:

Lewis, A. J.; Henderson, F. M.; Ryerson, R. A. (eds.) Principles and Applications of Imaging Radar: Manual of Remote Sensing. New York: John Wiley \& Sons, Chap. 5. pp. 271-356.

Brisco, B.; Brown, R. J.; Snider, B.; Sofko, G. J.; Koehler, J. A.; Wacker, A. G. 1991. Tillage effects on the radar backscattering coefficient of grain stubble fields. International Journal of Remote Sensing, 12(11), 2283-2298.

Canada Centre for Remote Sensing (CCRS). 1997. Educational resources for remote sensing: forest applications. Available at: <http://ftp.ccrs.nrcan.gc.ca/ftp/ad/MAS/globesar/por/ intro_p.pdf $>$. [Acessed 15 October 2017].

Cloude, S. R.; Pottier, E. A. 1996. Review of target decomposition theorems in radar polarimetry. IEEE Transactions on Geoscience and Remote Sensing, 34(2), 498-518.

Freeman, A.; Durden, S. L. 1998. A three-component scattering model for polarimetric SAR data. IEEE Transactions on Geoscience and Remote Sensing, 36(3), 963-973.

Freitas, C. C.; Sant'Anna, S. J. S.; Rennó, C. D.; Correia, A. H. 2007. Utilização de imagens de radar de abertura sintética na classificação de uso e ocupação do solo. [e-book] INPE. Available:

National Institute for Space Research < http://www.dpi.inpe.br/ofigeo.PDF> [Accessed 15 June 2017].

Hagensieker, R.; Waske, B. 2018. Evaluation of multi-frequency SAR images for tropical land cover mapping. Remote Sensing 10(2), 1-16.

Henderson, F. M.; Lewis, A. J. 1998. Manual of Remote Sensing: Principles and Applications of Imaging Radars. $3^{\text {rd }}$ ed. New York: John Wiley \& Sons.

Japan Aerospace Exploration Agency (JAXA). 2014. ALOS- 2 Project: PALSAR-2. Available at: <http://www.eorc.jaxa.jp/ALOS-2/en/about/palsar2.htm>. [Acessed 15 June 2017].

Kasischke, E. S.; Melack, J. M.; Dobson, M. C. 1997. The use of imaging radars for ecological applications - A review. Remote Sensing of Environment, 59 (2), 141-156. 
Kuplich, T. H.; Shimabukuro, Y. E.; Servello, E.; Sano, E. 2009. Polarimetric signatures and classification of tropical land covers. IEEE International Geoscience and Remote Sensing Symposium, IGARSS. 5, pp.118-121; doi: 10.1109/IGARSS.2009.5417717.

Landis, J. R.; Koch, G. G. 1977. The measurement of observer agreement for categorical data. Biometrics, 33(1), 159-174.

Lee, J. S.; Grunes, M. R.; Grandi, G. 1999. Polarimetric SAR speckle filtering and its implication for classification. IEEE Transactions on Geoscience and Remote Sensing, 37(5), 2363-2373.

Li, G.; Lu, D.; Moran, E.; Dutra, L.; Batistella, M. 2012. A comparative analysis of ALOS PALSAR Lband and RADARSAT-2 C-band data for land cover classification in a tropical moist region. ISPRS Journal of Photogrammetry and Remote Sensing, 70, 26-38.

Lu, D.; Li, G.; Moran, E.; Dutra, L.; Batistella, M. 2013. A comparison of multisensor integration methods for land cover classification in the Brazilian Amazon. GIScience e Remote Sensing, 48(3), 345-370.

Martins, F. S. R. V.; Santos, J. R.; Galvão, L. S.; Xaud, H. A. M. 2016. Sensitivity of ALOS/PALSAR imagery to forest degradation by fire in northern Amazon. ITC Journal, 49, 163-174.

Saatchi, S. S.; Dubayah, R.; Clark, D.; Chazdon, R.; Hollinger, D. 2010. Estimation of forest biomass change from fusion of radar and lidar measurements. Seminário de Atualização em Sensoriamento Remoto e Sistemas de Informações Geográficas Aplicados à Engenharia Florestal, 9.

Narvaes, I.; Santos J. R.; Silva, A. Q. 2010. Analysis of structural parameters of forest typologies using L-band SAR data. Bulletin of Geodetic Sciences, 16(3), 475-489.

Nery, C. V. M.; Fernandes, F. H. S.; Moreira, A. A.; Braga, F. L. 2013. Avaliação das técnicas de classificação MAXVER, MAXVER-ICM e distância mínima euclidiana de acordo com o índice Kappa. Revista Brasileira de Geografia Física, 6(2), 320-328.

Otukei, J. R.; Blaschke, T.; Collins, M. 2015. Fusion of Terra SAR-X and Landsat ETM+ data for protected area mapping in Uganda. International Journal of Applied Earth Observation and Geoinformation, 38, 99-104.

Pavanelli, J. A. P.; Santos, J. R.; Galvão, L. S.; Xaud, M. R.; Xaud, H. A. M. 2018. PALSAR-2/ALOS-2 and OLI/LANDSAT-8 data integration for land use and land cover mapping in northern Brazilian Amazon. Bulletin of Geodetic Sciences, 24(2), 249-268.

Pereira, L. O.; Freitas, C. C.; Sant'anna, J. S.; Reis, M. S. 2016. ALOS/PALSAR data evaluation for land use and land cover mapping in the Amazon region. IEEE Journal of Selected Topics in Applied Earth Observations and Remote Sensing, 9(12), 5413-5423.

Pereira, L. O.; Freitas, C. C.; Sant' Anna, S. J. S.; Lu, D.; Moran, E. F. 2013. Optical and radar data integration for land use and land cover mapping in the Brazilian Amazon. GIScience e Remote Sensing, 3(50), 301-321.

Santos, J. R.; Freitas, C. R.; Araújo, L. S.; Dutra, L. V.; Mura, J. C.; Gama, F. F.; Soler, L. S.; Sant'Anna, S. J. S. 2003. Airborne P-band SAR applied to the above ground biomass studies in the Brazilian tropical rainforest. Remote Sensing of Environment, 87(4), 482-493.

Silva, C. V. J. 2014. Caracterização florístico-estrutural e modelagem de biomassa na Floresta Amazônica a partir de dados ALOS/PALSAR e TERRASAR/TANDEM-X. M.Sc. in Remote Sensing. São José dos Campos: Instituto Nacional de Pesquisas Espaciais, 126 pp. 
Tadesse, H. K.; Qu, J. J.; Aguirre, A. A.; Komba, M.; Maggioni, V. 2017. Land use classification and analysis using radar data mining in Ethiopia. International Journal of Advanced Remote Sensing and GIS, 1(6), 2006-2022.

Treuhaft, R. N.; Law, B. E.; Asner, G. P. 2004. Forest attributes from radar interferometric structure and its fusion with optical remote sensing. BioScience, 54(6), 561-571. 